\title{
The long term impact of multiple micronutrient supplementation during infancy on cognition and executive function performance in pre-school children
}

\author{
M. Warthon-Medina ${ }^{1}$, P. Qualter ${ }^{1}$, N. Zavaleta ${ }^{2}$, S. Dillon ${ }^{1}$, F. Lazarte ${ }^{2}$ and N. M. Lowe ${ }^{1}$ \\ ${ }_{1}^{1}$ International Institute of Nutritional Sciences and Food Safety Studies, University of Central Lancashire, \\ Preston PRI 2HE, UK and ${ }^{2}$ Instituto de Investigación Nutricional, Lima, Perú
}

Evidence exists that deficiency of some micro-nutrients influences cognition in children ${ }^{(1)}$. Established key nutrients are iron, iodine, and folate which are all important for brain development and cognitive functions, and zinc, vitamin B12, and omega-3 polyunsaturated fatty acids may also be important ${ }^{(2)}$ particularly during the preschool years (1-5 year old), which is the main period of cognitive development due to a rapid and dramatic post-natal brain development that is dependent on the adequacy of nutrients ${ }^{(3)}$. Peru is considered a country at high risk of iron deficiency anaemia, and of zinc deficiency ${ }^{(4)}$ and evidence from observational studies suggests that micronutrients may play an important role in the cognitive development of children, but the results of intervention trials using single micronutrients are inconclusive ${ }^{(5)}$.

The aim of this study was to investigate the impact of multiple micronutrient (MMN) supplementation $v$. iron supplementation alone $(\mathrm{Fe})$ on cognitive and executive function performance in children. A randomized controlled trial was conducted in 2010 in the district of Villa El Salvador in the province of Lima, Peru in 902 children that received supplements at the age of 6-17 months. The iron group (control group) had received $12.5 \mathrm{mg}$ iron. The MMN group had received $12.5 \mathrm{mg}$ iron, $10 \mathrm{mg}$ zinc, $160 \mu \mathrm{g}$ folic acid, $30 \mathrm{mg}$ vitamin $\mathrm{C}$, and $300 \mu \mathrm{g}$ vitamin A. In 2012 a sub-sample of 184 children aged 36-48 months old of the original study sample were assessed with a range of cognitive tests involving the assessment of intelligence through the Wechsler Preschool and Primary Scale of Intelligence test, child's behaviour and competence through the Brief Infant Toddler Social Emotional Assessment (BITSEA) parent questionnaire, inhibitory control by the Day/Night Stroop test, working memory by 9 boxes, and executive function (state of reasoning) by the theory of mind (false belief task).

The multivariate analysis of variance (MANOVA) by group and gender group revealed non-significant differences between the Fe $(n$ 97) and MMN ( $n$ 87) groups for most cognitive tests (WPPSI executive scale, 9 boxes, theory of mind, BITSEA scores $(P>.05)$, with the exception of the vocabulary WPPSI verbal subtest in girls, $(\mathrm{MMN}$, (mean score $=6 \cdot 83, \mathrm{SD}=2 \cdot 05)$, iron $(\mathrm{mean}$ score $=5.78, \mathrm{SD}=1.59), P=0.028)$, where girls in the MMN had higher scores in the vocabulary test than girls in the Fe group. In contrast, there were some significant differences by gender for the following psychological tests: WPPSI verbal sentence subtest $(P=0 \cdot 039)$; day/night test longest correct run $(\mathrm{Fe}$ group, girls (mean score $=9, \mathrm{SD}=5 \cdot 12)$, boys $(\mathrm{mean}$ score $=6 \cdot 76, \mathrm{SD}=4 \cdot 35) v$. MMN group, girls (mean score $=9 \cdot 63$, $\mathrm{SD}=5 \cdot 37$ ), boys (mean score $=6 \cdot 81, \mathrm{SD}=4 \cdot 39), P=0 \cdot 011)$; and BITSEA test, where girls displayed higher competence scores than boys $(P=0.002)$ and boys had higher problem behaviour than girls $(P=0 \cdot 010)$.

Assessment of the impact of MMN on cognitive and social-emotional development in Peruvian preschool children determined that MMN supplements including zinc had no long term additional effects on cognitive function compared with iron alone, except for one subtest from the WPPSI verbal scale, which was the vocabulary subtest. Other co-variables should be taken into consideration such as the critical period of micronutrient deficiency, the timing and length of micronutrient supplementation and the response to psychological and socio-environmental factors. Further research is required to explore the effect of multiple micronutrient supplementation on cognitive function and psychomotor development post infancy.

This research was undertaken in collaboration with the Instituto de Investigación Nutricional (IIN). UNICEF conducted the original study. Supported by Funds for Women Graduates (FfWG) (http://ffwg.org.uk/).

1. Benton D (2010) The influence of dietary status on the cognitive performance of children. Mol Nutr Food Res 54(4), 457-70.

2. Bryan J, Osendarp S, Hughes D, Calvaresi E, Baghurst K, Van Klinken JW (2004) Nutrients for cognitive development in school-aged children. Nutr Rev 62(8), 295-306.

3. Rosales FJ, Reznick JS, Zeisel SH (2009) Understanding the role of nutrition in the brain and behavioral development of toddlers and preschool children: identifying and addressing methodological barriers. Nutr Neurosci 12(5), 190-202.

4. IZiNCG. International Zinc Nutrition Consultative Group (IZiNCG). Technical Brief. Quantifying the risk of zinc deficiency: Recommended indicators. http://www.a2zproject.org/pdf/English_brief1.pdf. 2007.

5. Nyaradi A, Li J, Hickling S, Foster J, Oddy WH. (2013) The role of nutrition in children's neurocognitive development, from pregnancy through childhood. Front Hum Neurosci 7. 